\title{
Comparison of Two Single-Incision Mini- Slings for the Treatment of Incontinence
}

\author{
Guner Yıldız $^{a} \quad$ Ali Furkan Batur ${ }^{b}$ Murat Akand ${ }^{b}$ Özcan Kılıçc Mehmet \\ Oğuz Şahin ${ }^{c}$ \\ aUrology Clinic, Health Sciences University Dr. Suat Seren Chest Diseases and Chest Surgery Training and Research \\ Hospital, Izmir, Turkey; b Department of Urology, Selçuk University, School of Medicine, Konya, Turkey; 'Urology \\ Clinic, Manisa State Hospital, Manisa, Turkey
}

\section{Highlights of the Study}

- Stress urinary incontinence is a serious public health problem for which an appropriate treatment is needed.

- Single-incision mini-sling systems are as effective as standard mid-urethral sling methods in the short term.

- This study showed that treatment of female urinary incontinence with single-incision mini-sling systems has minimal complications.

\section{Keywords}

Free anchorage technique $\cdot$ Mini-sling $\cdot$ Mid-urethral sling ·

Stress urinary incontinence

\begin{abstract}
Introduction: This study aimed to compare the safety and efficacy of 2 single-incision mini-sling (SIMS) systems with different designs of anchoring mechanism. Methods: The records of patients who have been operated for the treatment of female stress urinary incontinence (SUI) with 2 different SIMS systems were retrospectively evaluated. Patient characteristics, physical examination results, and quality of life (QoL) questionnaires were used to evaluate the patients. Primary efficacy endpoints were the cure and failure rates. Secondary efficacy endpoints were complications and differences in QoL questionnaires. Results: Eighty-three patients
\end{abstract}

from group 1 (Ophira SIMS system) and 77 patients from group 2 (Gallini SIMS system) were evaluated. There was no significant difference between the 2 groups regarding patient characteristics. The objective cure rates were found to be 83.1 and $79.2 \%$ in group 1 and group 2, respectively ( $p=$ 0.09 ). Mesh-related complications, such as anchor displacement, bladder erosion, vaginal erosion, and groin pain, were more common in group 1. No severe complications were observed. For both groups, a significant improvement in all scores of QoL questionnaires was observed after surgery; however, the differences between 2 groups were not significant. Conclusions: The present study showed that the treatment of female SUI with 2 different SIMS systems had similar efficacy, complication rates, and scores in QoL questionnaires. (c) 2020 The Author(s) Published by S. Karger AG, Basel

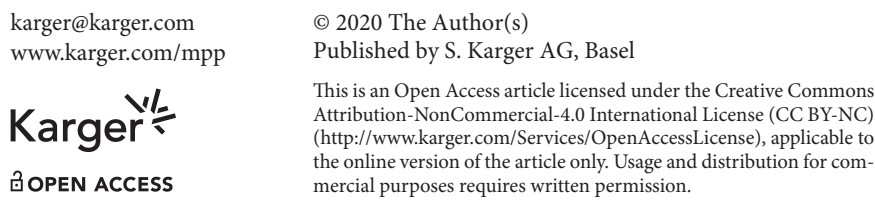

karger@karger.com www.karger.com/mpp

Karger $\stackrel{\text { ' }}{5}$

BOPEN ACCESS

(C) 2020 The Author(s)

Published by S. Karger AG, Basel

This is an Open Access article licensed under the Creative Commons Attribution-NonCommercial-4.0 International License (CC BY-NC) (http://www.karger.com/Services/OpenAccessLicense), applicable to the online version of the article only. Usage and distribution for commercial purposes requires written permission.

Ali Furkan Batur

Selçuk University School of Medicine

Celal Bayar Cd. No. 313

Selçuklu/Konya 42130 (Turkey)

alifurkanbatur@gmail.com 


\section{Introduction}

Urinary incontinence (UI) is a community health problem with a prevalence ranging between 25 and $40 \%$. Stress urinary incontinence (SUI) accounts for $50 \%$ of incontinent women [1]. Transabdominal surgeries were at the forefront for the treatment of SUI until Petros and Ulmsten proposed their integral theory on the pathophysiology of SUI [2]. Retropubic transvaginal tape (RPTVT) was 1st described among mid-urethral slings (MUS) in 1996 [3]. Then, Delorme has described transobturator tape (TOT) in 2001 [4]. Various studies conducted in the following years have shown that the effectiveness of RP-TVT and TOT was comparable. Although tension-free MUS surgery is the mainstay of SUI treatment for about 2 decades, its severe complications have impelled the researchers to improve MUS techniques [5]. Single-incision mini-sling (SIMS) was described as the 3rd-generation MUS surgery. SIMS systems, which have standard features such as a single vaginal incision and the same tape material (type 1 polypropylene), vary in size, application techniques, and designs of anchorage mechanism [6]. The 1st developed ones, such as TVT-Secur ${ }^{\mathrm{TM}}$ (Ethicon, Inc., Somerville, NJ, USA) and MiniArc ${ }^{\circledR}$ (American Medical Systems, Inc., Minnetonka, MN, USA), were tension free, and the efficacy of these SIMS systems was limited. Then, the adjustable SIMS systems were developed as a new category, which provide an insertion of the mesh into the obturator internus muscle/ membrane with different types of anchorage systems and also enable adjustment of the tape after the insertion [7]. The most crucial expectation in the development of SIMS surgeries is the low rate of serious complications due to the applicability with minimal dissection and absence of blind retropubic or groin muscle trajectories. Although there remain some controversial results regarding the short- and intermediate-term efficacy of the SIMS systems, some recent studies suggest that SIMS surgeries have comparable results with the MUS surgeries [7-9]. This study aimed to compare the safety and efficacy of the 2 SIMS systems with different designs of anchoring mechanism.

\section{Subjects and Methods}

This was a monocentric, retrospective, cohort study. The study was approved by the local ethics committee of Health Sciences University, Dr. Suat Seren Chest Diseases and Chest Surgery Training and Research Hospital (No. 49109414-806.02.02). The records of 273 patients who consecutively underwent SIMS sur- gery for SUI between 2013 and 2017 were retrospectively examined. One-year follow-up results were retrieved from the hospital records. Patients with a history of failed anti-incontinence surgery, radical pelvic surgery, pelvic radiation, urogynecological malignancy, pelvic trauma or fracture, and neurological disease and patients with concomitant grade 3 or higher cystocele, overactive bladder, overflow incontinence, and a postvoiding residue (PVR) volume of $>100 \mathrm{~mL}$ (at least 2 times) were excluded from the final analysis. After exclusion, 90 patients operated with the Ophira SIMS system (a sling with hard fishbone shape and low elasticity [Promedon, Cordoba, Argentina]) in group 1 and 90 patients operated with the Gallini SIMS system (a sling with soft fishbone shape that permits relative flexibility [Emerald, Italy]) in group 2 were included in the study. Seven patients from group 1 and 13 patients from group 2 were excluded due to missing data.

Parameters such as age, body mass index (BMI), menopause status, parity, duration of SUI, and smoking history were recorded. Physical abdominal and pelvic examination, pelvic ultrasound, and cough stress test (CST) were performed to all patients at baseline evaluation. Also, validated Turkish versions of International Consultation on Incontinence Questionnaire-Short Form (ICIQ-SF), Urogenital Distress Inventory (UDI-6), and Incontinence Impact Questionnaire (IIQ-7) forms were questioned before and after the surgery as part of routine evaluation, especially for the assessment of presence of urge predominant incontinence [10,11]. Pelvic ultrasound was used to evaluate PVR volume preoperatively.

All operations were performed by the same physician (G.Y.), with experience in pelvic floor disease surgery, under spinal anesthesia in the lithotomy position. A single dose of 1-gr 2nd-generation cephalosporin was administered intravenously $30 \mathrm{~min}$ before the operation for antibiotic prophylaxis. A Foley catheter was inserted before the operation to drain the bladder and was left inside for retraction during surgery.

Surgery techniques for the Ophira and Gallini systems were the same, except for the anchoring mechanisms. While the Ophira system had an anchor mechanism in the form of a hard fishbone, this mechanism consisted of a thinner soft serrated tip in the Gallini system (Fig. 1). Because of its physical structure, the Ophira system enters and clings tightly into the obturator internus muscle, but leaves a wide defect, causing tearing when it is intended to be pulled out. However, the very thin tip structure of the anchor of the Gallini system allows it to be pulled out with little tearing defect. An approximately $1-\mathrm{cm}$ vertical incision was made on the anterior vaginal wall $1 \mathrm{~cm}$ distal to the urethral orifice. Then, a sharp dissection was performed with scissors from both lateral sides of this incision. After reaching the level of the pubic ramus, a trocar or clamp was inserted toward the obturator internus muscle in both sides. Then, the mesh was placed and the tightness was adjusted by using Metzenbaum scissors. After that, the mesh was fixed to the obturator internus muscle on both sides. The vaginal wall was closed with 2.0 polyglactin sutures after bleeding control was achieved. The procedure was completed by inserting the nitrofurazone/rifamycin-impregnated tampons into the vagina.

Tampons and Foley catheter were removed on postoperative day 1 , and patients were discharged on the same day after normal voiding was observed. Also, PVR was checked in all patients; PVR $<100 \mathrm{~mL}$ was the goal. The patients were discharged with an information document about medications and the schedule of followup visits. 
Fig. 1. Fig. 1. Anchor mechanisms of the single incision minisling systems used. a Ophira system, hard fishbone, b Gallini system, soft serrated tip.
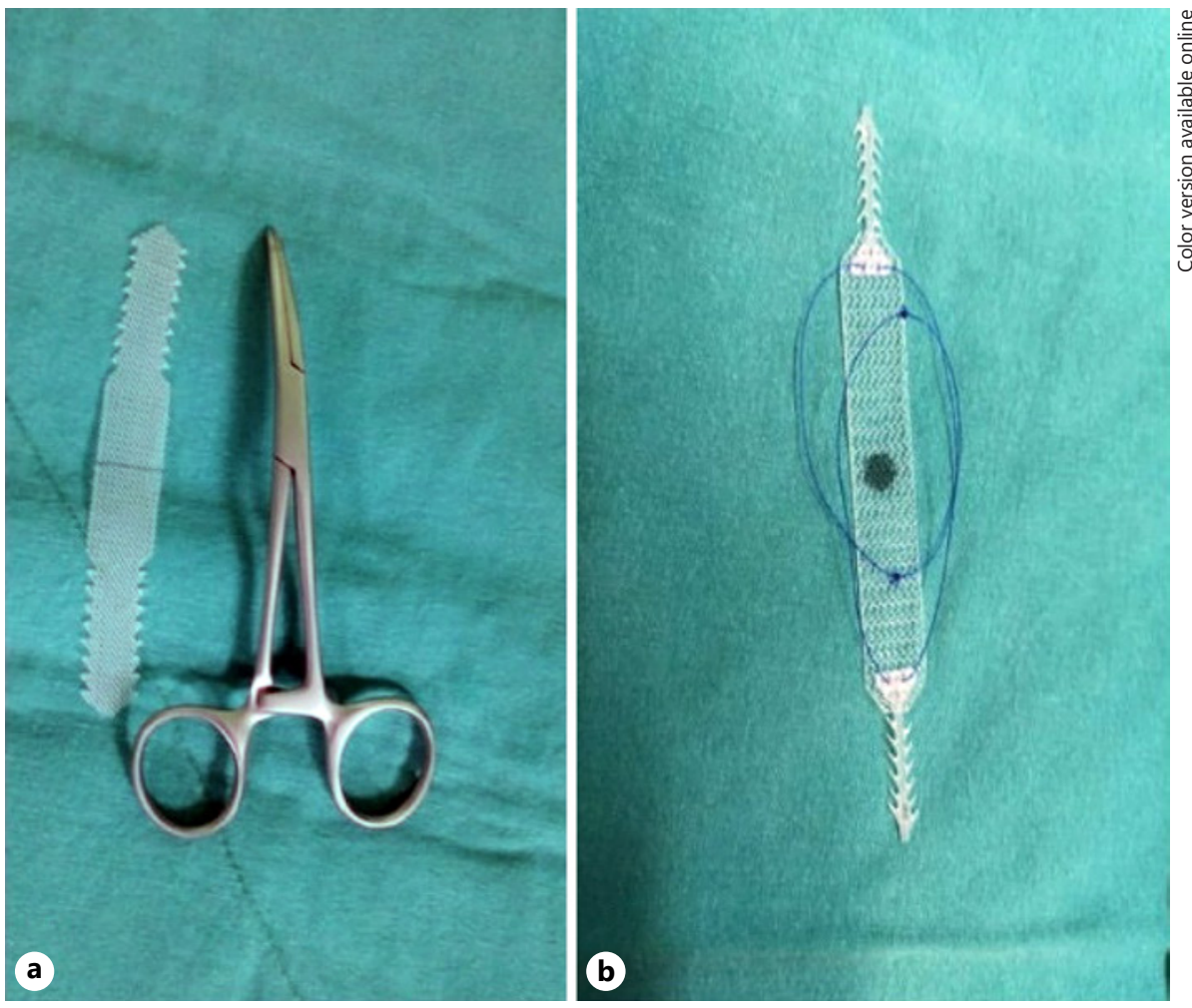

All patients were followed up by the same urologist as part of the standardized follow-up schema on postoperative day 5 and 1st, $3 \mathrm{rd}$, 6th, and 12th months. The follow-up visit on the 5th day was performed to check any postoperative complications, such as hematoma, wound infection, sepsis, or voiding dysfunction. Postoperative continence rates were evaluated by using standardized CST, which was applied at lithotomy and standing positions with the bladder filled with $300 \mathrm{~mL}$ of saline. The patients were asked to cough 5 consecutive times in each position, and any incontinence was considered positive. The severity of the incontinence was defined according to the Ingelheim-Sunberg scale [12]. Although detailed evaluation of sexual functions with Female Sexual Function Index (FSFI) or Pelvic Organ Prolapse-Urinary Incontinence Sexual Questionnaire (PISQ-12) inquiry forms was not performed in this study, all patients were questioned for postoperative dyspareunia.

Primary efficacy endpoints were the objective cure, subjective cure, and failure rates of the treatment in 1 year after surgery. The patient-reported improvement with negative CST was considered as the objective cure, while improvement with positive CST was considered as the subjective cure. Failure was considered to be no improvement with a positive CST. Secondary efficacy endpoints were complications reported according to the modified ClavienDindo classification and difference in quality of life (QoL) questionnaires.

Statistical analyses were performed using SPSS version 21 (SPSS Inc., Chicago, IL, USA). The Mann-Whitney U test was used to compare the 2 groups regarding the nonparametric variables. The paired $t$ test was used to test for the continuous parametric variables, while Fisher's exact test was used to test for the continu- ous nonparametric variables. In all statistical analysis, $p<0.05$ was deemed statistically significant.

A priori power analysis was conducted using "pwr" packages in R 3.6.0 (www.r-project.org) to test the difference between 2 independent groups using a two-tailed test, a medium effect size $(d=0.50)$, and an alpha of 0.05 . The result showed that a total sample of 172 participants with 2 equal-sized groups of $n=86$ were required to achieve a power of 0.90 .

\section{Results}

Mean ages of the patients were $53 \pm 12.5$ and $51 \pm 10.3$ in groups 1 and 2, respectively. No significant difference was observed for BMI between the groups. Most of the patients were postmenopausal in both groups. The average duration of SUI was $3.7 \pm 2.1$ and $4.1 \pm 2.5$ years for groups 1 and 2, respectively $(p=0.69)$. Patient characteristics are summarized in Table 1. All patients in both groups had preoperatively a positive CST, of whom 11 from each group were with grade 3 according to the Ingelman-Sundberg scale (Table 2).

The mean operating times were $7.2 \pm 2$ and $7.4 \pm 2.5$ min in groups 1 and 2 , respectively, with no statistical difference $(p=0.8)$. No severe intraoperative complications, such as hematuria, vaginal wall laceration, bladder or ure- 
Table 1. Demographics and preoperative characteristics

\begin{tabular}{lccl}
\hline & $\begin{array}{c}\text { Group 1 } \\
(n=83)\end{array}$ & $\begin{array}{c}\text { Group 2 } \\
(n=77)\end{array}$ & $\begin{array}{l}p \\
\text { value }\end{array}$ \\
\hline Age, yr & $53 \pm 12.5$ & $51 \pm 10.3$ & 0.81 \\
BMI & $27.9 \pm 3.5$ & $28.7 \pm 4.5$ & 0.67 \\
Parity & $2.5 \pm 1.5$ & $2.9 \pm 1.3$ & 0.73 \\
Menopause, \% & $55(66.3)$ & $49(63.6)$ & 0.57 \\
History of smoking, yr & $19(22.8)$ & $20(25.9)$ & 0.63 \\
Duration of SUI average, yr & $3.7 \pm 2.1$ & $4.1 \pm 2.5$ & 0.69 \\
\hline
\end{tabular}

Data are expressed as mean \pm SD or $n(\%)$, unless otherwise specified. Group 1, patients operated with the Ophira mini-sling system; Group 2, patients operated with the Gallini mini-sling system; BMI, body mass index $\left(\mathrm{kg} / \mathrm{m}^{2}\right)$; $\mathrm{yr}$, year.

Table 2. Cough stress test

\begin{tabular}{llll}
\hline & $\begin{array}{l}\text { Group 1 } \\
(n=83)\end{array}$ & $\begin{array}{l}\text { Group 2 } \\
(n=77)\end{array}$ & $\begin{array}{l}p \\
\text { value }\end{array}$ \\
\hline Positive cough stress test & 83 & 77 & \\
Grade I* & $23(27.8 \%)$ & $23(29.9 \%)$ & 0.79 \\
Grade II* & $49(59 \%)$ & $43(55.8 \%)$ & 0.23 \\
Grade II* & $11(13.2 \%)$ & $11(14.3 \%)$ & 0.84 \\
\hline
\end{tabular}

Group 1, patients operated with the Ophira mini-sling system; Group 2, patients operated with the Gallini mini-sling system. * The Ingelman-Sundberg scale was used for grading.

Table 3. Objective and subjective cure rates and failure rates after 1 year of follow-up

\begin{tabular}{lccl}
\hline & $\begin{array}{l}\text { Group 1 } \\
(n=83)\end{array}$ & $\begin{array}{l}\text { Group 2 } \\
(n=77)\end{array}$ & $\begin{array}{l}p \\
\text { value }\end{array}$ \\
\hline Objective cure & $69(83.1 \%)$ & $61(79.2 \%)$ & 0.097 \\
Subjective cure & $5(6 \%)$ & $6(7.7 \%)$ & 0.43 \\
Failure & $9(10.8 \%)$ & $10(12.9 \%)$ & 0.49 \\
\hline
\end{tabular}

Group 1, patients operated with the Ophira mini-sling system; Group 2, patients operated with the Gallini mini-sling system.

thral injury, major bleeding episodes, or clinical hematoma formation, were observed in any patient. All patients were discharged on the 1st day after operation.

The objective cure rates at 12-month follow-up were found to be similar in groups 1 and 2 with no significant difference. During the same follow-up time, subjective cure and failure rates were also similar in both groups (Table 3).

Postoperative complications were observed in 11 and 3 patients in groups 1 and 2, respectively, of which all were mild. Two cases of anchor displacement with mesh erosion were only observed in group 1. Bladder erosion was also experienced by 2 patients in group 1. These 4 cases were successfully treated with removal of mesh under spinal anesthesia. No urethral erosion was seen in either group. Vaginal erosion was observed in 3 and 2 patients in groups 1 and 2, respectively, which was treated with resection under local anesthesia on an outpatient procedure (Table 4).

None of the patients experienced postoperative voiding dysfunction, such as urinary retention, difficulty in urination, or significantly increased PVR. De novo urge incontinence, which was detected in the control visit at postoperative month 3 , was developed in 5 patients in each group ( 7.2 vs. $7.7 \%, p=0.8$ ). All of these patients were successfully treated with oral anticholinergic therapy. Pre- and postoperative ICIQ-SF, IIO-7, and UDI-6 scores for both groups are summarized in Table 5. A significant improvement in all scores of these questionnaires was observed after surgery in both groups; however, the differences between these 2 groups were not significant. Dyspareunia was observed only in 3 (3.6\%) and 2 (2.5\%) patients with vaginal mesh erosion in groups 1 and 2 , respectively. Postoperative mild groin pain was seen in 2 (2.4\%) and $1(2.5 \%)$ patient in groups 1 and 2, respectively. However, the groin pains were not permanent and were treated successfully with oral anti-inflammatory medication.

\section{Discussion}

The main objective in the development of the SIMS systems was to reduce morbidities while attaining comparable success rates with that of conventional MUS surgeries. In this study, the total cure rates were observed to be 89.1 and $86.9 \%$ in groups 1 and 2, respectively. The short-term cure rates of SIMS systems range between 89.4 and $94.4 \%$ in the literature, and these rates, including ours, are comparable with the results of the conventional transobturator MUS surgeries [7, 13-17].

On the other hand, the cure rates of the 1st-generation tension-free mini-slings were variable, with objective cure rates varying between 76 and $95.3 \%$, and success rates decrease as time passes [18]. The most studied sling systems were TVT-Secur ${ }^{\mathrm{TM}}$ (Ethicon, Inc., Somerville, NJ, 
Table 4. Complications

\begin{tabular}{lllll}
\hline Complication & $\begin{array}{l}\text { Group 1 } \\
(n=83)\end{array}$ & $\begin{array}{l}\text { Group 2 } \\
(n=77)\end{array}$ & $p$ value & $\begin{array}{l}\text { Modified Clavien-Dindo } \\
\text { classification system }\end{array}$ \\
\hline Trocar replacement & $2(2.4 \%)$ & 0 & 0.15 & Grade 3a \\
Bladder erosion & $2(2.4 \%)$ & 0 & 0.15 & Grade 3a \\
Vaginal erosion & $3(3.6 \%)$ & $2(2.6 \%)$ & 0.63 & Grade 3a \\
Anchor displacement & $2(2.4 \%)$ & 0 & 0.4 & Grade 3a \\
Postoperative mild groin pain & $2(2.4 \%)$ & $1(1.2 \%)$ & 0.4 & Grade 1 \\
De novo urge incontinence & $5(6 \%)$ & $5(6.4 \%)$ & 0.4 & Grade 2 \\
Dyspareunia - those with vaginal erosion & $3(3.6 \%)$ & $2(2.6 \%)$ & 0.63 & Grade 3a \\
\hline
\end{tabular}

Group 1, patients operated with the Ophira mini-sling system; Group 2, patients operated with the Gallini mini-sling system.

Table 5. Comparison of groups in terms of questionnaires

\begin{tabular}{lccc}
\hline Analysis & $\begin{array}{l}\text { Group 1 } \\
(n=83)\end{array}$ & $\begin{array}{l}\text { Group 2 } \\
(n=77)\end{array}$ & $p$ value \\
\hline ICIQ-SF & $13(11-21)$ & $15(11-21)$ & 0.36 \\
PREOP & $1(0-20)$ & $1(0-20)$ & 0.33 \\
POSTOP & $<0.05$ & $<0.05$ & \\
$p$ value & & & \\
\hline$I I Q-7$ & $14(11-21)$ & $15(11-21)$ & 0.72 \\
PREOP & $1(0-21)$ & $1(0-20)$ & 0.83 \\
POSTOP & $<0.05$ & $<0.05$ \\
$p$ value & $11(0-14)$ & $11(9-13)$ & 0.47 \\
\hline UDI-6 & $1(0-10)$ & $1(0-12)$ & 0.29 \\
PREOP & $<0.05$ & $<0.05$ & \\
POSTOP & & \\
$p$ value & &
\end{tabular}

Group 1, patients operated with the Ophira mini-sling system; Group 2, patients operated with the Gallini mini-sling system. ICIQ-SF, International Consultation on Incontinence Questionnaire-Short Form; IIQ-7, incontinence impact questionnaire; UDI-6, urogenital distress inventory. Data are expressed as median (min-max).

USA) and MiniArc ${ }^{\circledR}$ (American Medical Systems, Inc., Minnetonka, MN, USA) among these tension-free minislings. TVT-Secur has been withdrawn from the market with a sudden decision of the manufacturer, citing to these unfavorable mid-term clinical results [19].

However, positive reports on the long-term efficacy results related to the SIMS systems, also which we have used in our study, have been published recently. Of these, Gon et al. [20] reported a success rate of $67.5 \%$ and an improvement rate of $17.5 \%$ at 8 -year follow-up in their study of 40 patients who were operated with the Ophira system for SUI. According to the results of the same study, it was stated that this success rate increased to $85 \%$ in patients who had not previously had SUI surgery [20]. Similarly, Golbasi et al. [21] reported approximately $80 \%$ of patientreported success rates in their study, including 62 patients operated with the Ophira system at 30-month follow-up.

SIMS surgeries have a significant advantage of short operation duration and applicability under local or epidural anesthesia $[7,16,17]$. Literature data show that the mean operation durations vary between 7 and 13 min $[14,22]$. Our mean operating time was in accordance with this data. SIMS surgeries are also reported to be safe in the literature with very low rates of severe complications, especially in experienced centers $[7,17,23,24]$. In parallel with this, no severe intraoperative complications and no postoperative urinary retention or incomplete bladder emptying (PVR $>100 \mathrm{~mL}$ ) were observed in any patient in our study.

Mesh-related complications, such as anchor displacement, vaginal erosion, and groin pain, were more common in group 1, which might be associated with the rigid structure of Ophira system. Local excision of the mesh was enough to treat these complications. Mesh erosion ratios vary between 1.1 and $11.9 \%$ in the literature [22, $24]$. Our vaginal erosion rates were 3.6 and $2.6 \%$ in groups 1 and 2 , respectively $(p=0.6)$. Excessive tension of the mesh, intense sexual intercourse during early postoperative period, and/or mesh characteristics are the factors that are blamed for the mesh erosions. Local excision and local estrogen therapy are the recommended choices in the treatment of mesh erosions $[25,26]$.

Patients operated with mini-sling systems were reported to have shorter recovery times [7]. Besides, various studies have shown that mini-sling operations have im- 
proved the QoL of the patients $[14,27,28]$. The differences between preoperative and postoperative scores in each questionnaire (ICIQ-SF, IIQ-7, and UDI-6) were significant in both groups in this study, indicating an improvement in the QoL of the patients independent from the SIMS system used. De novo urge incontinence was developed in 6 and $6.4 \%$ of the patients in groups 1 and 2 , respectively, in the present study. There are conflicting de novo urgency rates after SIMS surgery in the literature. A recent systematic review stated a higher trend regarding de novo urgency or worsening of pre-existing urgency after the SIMS surgeries [17].

The evaluation of sexual function has not been performed in most of the previous studies. Two randomized controlled trials (RCT) have evaluated sexual function by using the PISQ-12 [15, 17]. Rudnicki et al. [15] found low de novo dyspareunia rates and no statistical difference between the groups in their RCT comparing the SIMS with the conventional MUS. In our study, dyspareunia was developed in $5(3.1 \%)$ patients with vaginal mesh erosion. Dyspareunia was observed in $3(3.6 \%)$ and 2 (2.5\%) patients in groups 1 and 2, respectively.

This study has some limitations. The retrospective design of the study might have led to some selection bias. Mainly, strict criteria for inclusion might have led to inclusion of less complicated patients to the study. Short follow-up duration is another limitation of our study. The relatively small number of patients who have a BMI of $>30 \mathrm{~kg} / \mathrm{m}^{2}$ in this study makes it difficult to give a definitive judgment regarding the effectiveness of these surgeries in obese patients. Although the presence of dyspareunia has been questioned pre- and postoperatively, it is a limitation that sexual functions have not been questioned by using specific questionnaires.

\section{Conclusion}

Our results show excellent short-term cure rates of both SIMS systems with no severe complications. A limited number of publications reporting on intermediateand long-term outcomes of SUI patients operated with SIMS systems exist in the literature. All these studies show the success of mini-sling surgeries and comparable results with conventional sling surgeries. The ease of learning and application of mini-sling surgeries, which have a much lower complication rate compared to conventional sling surgeries, is another advantage. Besides, there is currently an intense debate about the use of mesh in vaginal surgeries. Therefore, prospective randomized larger studies are required for mini-sling surgeries that use less mesh material than conventional sling methods.

\section{Statement of Ethics}

This was a monocentric, retrospective, cohort study. The study was approved by the local ethics committee of Health Sciences University, Dr. Suat Seren Chest Diseases and Chest Surgery Training and Research Hospital (No. 49109414-806.02.02). Written informed consent was obtained from all patients before the operation as part of the routine application. All patients were informed that there was still a lack of evidence regarding the longterm efficacy results of mini-sling surgeries.

\section{Conflict of Interest Statement}

The authors declare that they have no conflicts of interest related to this article.

\section{References}

1 Irwin DE, Kopp ZS, Agatep B, Milsom I, Abrams P. Worldwide prevalence estimates of lower urinary tract symptoms, overactive bladder, urinary incontinence and bladder outlet obstruction. BJU Int. 2011;108(7): $1132-8$.

2 Petros PE, Ulmsten U. Urethral pressure increase on effort originates from within the urethra, and continence from musculovaginal closure. Neurourol Urodyn. 1995;14(4):33750.

3 Ulmsten U, Henriksson L, Johnson P, Varhos G. An ambulatory surgical procedure under local anesthesia for treatment of female urinary incontinence. Int Urogynecol J Pelvic Floor Dysfunct. 1996;7(2):81-6.
4 Delorme E. Transobturator urethral suspension: mini-invasive procedure in the treatment of stress urinary incontinence in women. Prog Urol. 2001;11:1306-13.

5 Burkhard FC, Lucas MG, Berghmans LC, Bosch JLHR, Cruz F, Lemack GE, et al. EAU guidelines on urinary incontinence in adults. Eur Assoc Urol. 2016;59:387-400.

6 Mostafa A, Lim CP, Hopper L, Madhuvrata P, Abdel-Fattah M. Single-incision mini-slings versus standard midurethral slings in surgical management of female stress urinary incontinence: an updated systematic review and meta-analysis of effectiveness and complications. Eur Urol. 2014;65(2):402-27.
7 Bai F, Chen J, Zhang Z, Zheng Y, Wen J, Mao $\mathrm{X}$, et al. Adjustable single-incision mini-slings $\left(\right.$ Ajust ${ }^{\oplus}$ ) versus other slings in surgical management of female stress urinary incontinence: a meta-analysis of effectiveness and complications. BMC Urol. 2018;18:1-10.

8 Abdel-Fattah M, Ford JA, Lim CP, Madhuvrata $P$. Single-incision mini-slings versus standard midurethral slings in surgical management of female stress urinary incontinence: a meta-analysis of effectiveness and complications. Eur Urol. 2011;60(3):468-80.

9 Ogah J, Cody DJ, Rogerson L. Minimally invasive synthetic suburethral sling operations for stress urinary incontinence in women: a short version Cochrane review. Neurourol Urodyn. 2011;30(3):284-91. 
10 Çetinel B, Özkan B, Can G. The validation study of ICIQ-SF Turkish version. Turk Urol Derg. 2004;30:332-8.

11 Cam C, Sakalli M, Ay P, Cam M, Karateke A. Validation of the short forms of the incontinence impact questionnaire (IIQ-7) and the urogenital distress inventory (UDI-6) in a Turkish population. Neurourol Urodyn. 2007;26(1):129-33.

12 Chapple C. Classification of mixed incontinence. Eur Urol Suppl. 2006;5:837-41.

13 Grigoriadis C, Bakas P, Derpapas A, Creatsa $M$, Liapis A. Tension-free vaginal tape obturator versus Ajust adjustable single incision sling procedure in women with urodynamic stress urinary incontinence. Eur J Obstet Gynecol Reprod Biol. 2013;170(2):563-6.

14 Xin X, Song Y, Xia Z. A comparison between adjustable single-incision sling and tensionfree vaginal tape-obturator in treating stress urinary incontinence. Arch Gynecol Obstet. 2016;293(2):457-63.

15 Rudnicki M, von Bothmer-Ostling K, Holstad A, Magnusson C, Majida M, Merkel C, et al. Adjustable mini-sling compared with conventional mid-urethral slings in women with urinary incontinence. A randomized controlled trial. Acta Obstet Gynecol Scand. 2017; 96(11):1347-56.

16 Abdel-Fattah M, Agur W, Abdel-All M, Guerrero K, Allam M, MacKintosh A, et al. Prospective multi-centre study of adjustable single-incision mini-sling (Ajust ${ }^{\circledR}$ ) in the management of stress urinary incontinence in women: 1-year follow-up study. BJU Int. 2012;109:880-6.

17 Mostafa A, Agur W, Abdel-All M, Guerrero K, Lim C, Allam M, et al. Multicenter prospective randomized study of single-incision mini-sling vs tension-free vaginal tape-obturator in management of female stress urinary incontinence: a minimum of 1-year followup. Urology. 2013;82(3):552-9.

18 Leanza V, Intagliata E, Leanza A, Ferla F, Leanza G, Vecchio R. Comparison between three mini-sling surgical procedures and the traditional transobturator vaginal tape technique for female stress urinary incontinence. G Chir. 2014;35(3-4):80-4.

19 Cornu JN, Sèbe P, Peyrat L, Ciofu C, Cussenot $\mathrm{O}, \mathrm{Haab}$ F. Midterm prospective evaluation of TVT-Secur reveals high failure rate. Eur Urol. 2010;58(1):157-61.

20 Mira Gon L, Zanettini Riccetto CL, Citatini de Campos CC, Iamashita Voris BR, Reis LO, Rodrigues Palma PC. Mini-sling Ophira at 8 years follow-up: does it sustain results? Urol Int. 2019;102(3):326-30.

21 Golbasi C, Taner CE, Golbasi H. Long-term outcomes and quality of life effects of single incision mini sling procedure in stress urinary incontinence patients. Eur J Obstet Gynecol Reprod Biol. 2019;234:10-3.

22 Taner CE, Okay G, Göklü Y, Başoğul Ö, Başoğul N. Perioperative and postoperative complications after Ophira mini sling operations. Arch Gynecol Obstet. 2015;291(2):341-6.
23 Han $\mathrm{H}$, Wang B, Xu Y, Zhang X, Zhang P, Fan $B$. Meta-analysis of female stress urinary incontinence treatments with adjustable singleincision mini-slings and transobturator tension-free vaginal tape surgeries. BMC Urol. 2015;15:1-7.

24 Madsen AM, El-Nashar SA, Woelk JL, Klingele CJ, Gebhart JB, Trabuco EC. A cohort study comparing a single-incision sling with a retropubic midurethral sling. Int Urogynecol J. 2014;25(3):351-8.

25 Kershaw V, Nicholson R, Ballard P, Khunda A, Puthuraya S, Gouk E, et al. Randomized controlled trial comparing single-incision mini-sling and transobturator midurethral sling for the treatment of stress urinary incontinence: 3-year follow-up results. Neurourol Urodyn. 2019;17:40-8.

26 Bergersen A, Hinkel C, Funk J, Twiss CO. Management of vaginal mesh exposure: a systematic review. Arab J Urol. 2019;17(1):40-8.

27 Meschia M, Barbacini P, Baccichet R, Buonaguidi A, Maffiolini M, Ricci L, et al. Shortterm outcomes with the Ajust ${ }^{\text {tw }}$ system: a new single incision sling for the treatment of stress urinary incontinence. Int Urogynecol J. 2011; 22:177-82.

28 Naumann G, Hagemeier T, Zachmann S, AlAni A, Albrich S, Skala C, et al. Long-term outcomes of the Ajust adjustable single-incision sling for the treatment of stress urinary incontinence. Int Urogynecol J. 2013;24(2): 231-9. 